\title{
AN INBORN ERROR OF METABOLISM WITH THE URINARY EXCRETION OF $\alpha$-HYDROXY-BUTYRIC ACID AND PHENYLPYRUVIC ACID
}

\author{
BY \\ ALAN J. SMITH and LEONARD B. STRANG \\ From the Departments of Chemical Pathology and Child Health, King's College, University of Durham
}

(RECEIVED FOR PUBLICATION OCTOBER 3, 1957)

We have recently seen a baby girl with gross mental deficiency who had repeated attacks of generalized oedema. She also had an extremely unpleasant, pungent smell due to the presence in her urine of a substance derived from $\alpha$-hydroxy-butyric acid. So far as we know, this acid has not previously been detected in human urine. The urine also contained phenylpyruvic acid and phenylacetic acid as well as an excess of certain amino-acids.

We believe that the infant had a double metabolic abnormality. One was the familiar defect of phenylketonuria in which a block in the conversion of phenylalanine to tyrosine leads to the accumulation of phenylalanine in the body and to the excretion in the urine of phenylpyruvic acid, phenylacetic acid and other derivatives of phenylalanine (Jervis, 1954). The urinary excretion of $\alpha$-hydroxybutyric acid cannot be related to the metabolism of phenylalanine and indicates the presence of another metabolic defect.

\section{Clinical History}

Mary D. was the first baby of healthy, unrelated parents, and was born normally in a maternity hospital. She breathed and cried at birth but from the beginning she refused the breast. From the first day of life she had an unusual and unpleasant smell. On the fourth day she developed occasional extensor spasms and was extremely pale, listless and unresponsive to stimuli. She was at that time thought to have a severe cerebral abnormality.

On the ninth day of life she first came under our observation. She was quite flaccid and unresponsive to stimuli. The fontanelle tension was increased and the head circumference was 14 inches. She lay motionless and required tube feeding. The curious smell which had been noticed on the first day of life was still present. It hung about her room and clung to her clothes and the clothes of those who nursed her. It was described by different observers as smelling 'like an oast house', 'like burnt sugar' and 'like dried celery'. The source of the smell was her urine.
Further investigations at this time gave the following results:

Lumbar Puncture. Normal pressure, clear fluid, no cells and protein $120 \mathrm{mg} . / 100 \mathrm{ml}$.

Subdural Puncture. There was no evidence of subdural collections.

Serum. The urea level was $41 \mathrm{mg}$. $/ 100 \mathrm{ml}$., potassium $3.1 \mathrm{mEq} . / 1$, calcium $5.1 \mathrm{mEq} . / 1$ and total protein $7 \cdot 8 \mathrm{~g} . / 100 \mathrm{ml}$.

During the first six weeks of life she improved sufficiently to feed from a bottle and was able to go home. She remained hypotonic and completely unresponsive to stimuli, never taking notice of anything or attempting to raise her head. She had long spells of loud, monotonous crying little affected by sedation.

Between the ages of 5 and 10 months she had frequent episodes of fever, rapid breathing and generalized pitting oedema. There was no evidence of congestive heart failure. The first attack was regarded as due to infection and treated with chemotherapy. Subsequently, however, she often recovered within a matter of 12 to 24 hours from attacks for which no chemotherapy was given.

At 9 months she had grown a small amount of completely white hair. She had also increased in size (weight $20 \mathrm{lb}$. and head circumference 17 inches) but remained mentally defective and responsive only to painful stimuli. The characteristic smell persisted in the urine throughout life. At $\mathbf{1 0}$ months she died at home.

\section{Necropsy Report}

Dr. J. Hart-Mercer reported as follows:

The body weighed $7.75 \mathrm{~kg}$. (within normal limits). It was 'well nourished', i.e., the subcutaneous fat was abundant, measuring up to $1.5 \mathrm{~cm}$. on the anterior abdominal wall. The head circumference was $42 \mathrm{~cm}$. (a little small for the age). The scalp hair was very blonde and fine.

The internal appearance showed evidence of terminal inhalation of bilious vomit into the bronchi.

The thymus $(12 \mathrm{~g}$.) showed some degree of accidental involution. 
There were a few fibrous pleural adhesions in the left interlobar fissure, and marginal emphysema and moderate emphysema bilaterally. Foci of broncho-pneumonia were found in both lungs, particularly in the lower lobes, associated microscopically with pneumococci.

All the chambers of the heart were slightly dilated.

The liver was slightly enlarged (to $284 \mathrm{~g}$.) and microscopically merely showed venous congestion with centrilobular degenerative and atrophic changes in the liver cells.

The spleen weighed $17 \mathrm{~g}$. and was a little smaller than normal. It showed fleckmilz, i.e., multiple small foci of recent and developing necrosis affecting irregular areas of pulp and lymphoid tissue. Resembling early infarcts, they were not apparently associated with gross arterial change but recent thrombi were encountered in occasional arterioles.

The kidneys weighed together $133 \mathrm{~g}$., about twice the normal combined weight. The enlargement was bilateral and diffuse, the subcapsular surfaces smooth, the cortices pale. Microscopy showed hypertrophic-looking proximal convoluted tubules lined by unusually tall epithelium. In many of these cells there was hyaline droplet degeneration.

The glomeruli were largely unaltered, but here and there thrombus or thrombus-like eosinophilic material occluded one or more capillary loops.

The cells of the lower nephrons frequently showed lipid droplets in their cytoplasm and occasionally their lumen was distended with hyaline cast material.

The brain weighed 700 g., a little small for the age. Neither externally nor on section was there evidence of gross maldevelopment. Indeed the appearances were almost normal. The width of the white matter in the cerebral hemispheres may have been slightly reduced but the only convincing change was the unduly soft consistency of all parts of the brain.

Microscopic examination showed widespread changes in cerebrum, brain-stem and cord suggesting a nutritional encephalomyelopathy with widespread defect of myelinization.

\section{Examination of Urine}

The urine during life was a clear, amber-coloured liquid with the characteristic penetrating smell already described and which did not diminish during storage at $4^{\circ} \mathrm{C}$. The reaction was acid to litmus, no albumin was present and no formed elements were found on repeated microscopy.

The first specimen gave a slight reduction with Benedict's qualitative reagent on one occasion which was shown to be due to glucuronic acid.

Phenylketonuria. The addition of a few drops of ferric chloride to the urine gave a fairly persistent emerald green colour which was consistent with the presence of phenylpyruvic acid. The colour was more intense if the urine was acidified, extracted with ether and a drop of ferric chloride added to the extract. The characteristic smell was found to be extracted at the same time; since this did not happen when alkaline urine was similarly extracted it could be concluded that the pungent-smelling substance was acid in nature. The phenylpyruvic acid was quantitatively estimated by a slight modification of the method of Berry and Woolf (1952). A freshly synthesized and purified sample of phenylpyruvic acid (Herbst and Shemin, 1939) was used for the calibration curve. The concentration was found to be $8.96 \mathrm{mg}$. $/ 20 \mathrm{ml}$. urine or $134.4 \mathrm{mg}$. $/ 24$ hours.

Phenylpyruvic acid is an oxo-acid and as further confirmation of its presence it was decided to make 2.4 dinitrophenylhydrazine derivatives of all the oxoacids in the urine by the method of Cavallini, Frontali and Toschi (1949). The extract of the derivatives from the urine was compared chromatographically with derivatives prepared from a series of oxo-acids. The $2 \cdot 4$ dinitrophenylhydrazine derivative of phenylpyruvic acid was prepared from the freshly synthesized acid by the method of Smith and Jones (1948). The solvent phase of tert-amyl alcohol, 50 parts; ethyl alcohol, 10 parts; water, 40 parts, was used as the developing solvent (Altmann, Crook and Datta, 1951) on Whatman No. 3

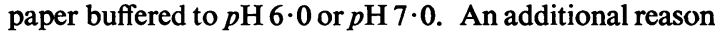
for examining these oxo-acid derivatives was the fact that the acids in dilute solution in water have smells somewhat similar to that of the urine.

The keto-acids chosen were $\alpha$-oxo-butyric, oxoglutonic, pyruvic, $\alpha$-oxo-glutaric, acetoacetic, p-hydroxyphenylpyruvic, oxo-malonic and laevulinic. The spots needed no development since the derivatives were yellow. The phenylpyruvic acid derivatives had an $R_{F}$ of 0.66 on paper buffered to $p \mathrm{H} 6.0$ and 0.60 on paper buffered to $p \mathrm{H} 7 \cdot 0$.

The urine showed only one derivative which had the same $R_{F}$ as the phenylpyruvic acid on paper at both $p \mathrm{H} 6.0$ and $p \mathrm{H} \mathrm{7.0.} \mathrm{This} \mathrm{was} \mathrm{a} \mathrm{useful} \mathrm{confirmatory} \mathrm{test}$ for phenylpyruvic acid. Nearer the solvent there was a discrete unstained area of the paper which contained a substance with the characteristic smell of the patient's urine. The smell was therefore not due to an oxo-acid. It was easy to demarcate the area by smell and so assign an $\mathbf{R}_{\mathbf{F}}$ value of about 0.8 to the unknown colourless substance.

The Identification of the Unknown Substance. In order to identify this strongly smelling non-ketonic, ethersoluble substance, a $25 \mathrm{ml}$. sample of urine was acidified to $p \mathrm{H} 1.0$ with concentrated $\mathrm{HCl}$ and extracted three times with $25 \mathrm{ml}$. ether. The combined extracts were evaporated by a stream of nitrogen and the residue dissolved in a small volume of ether. This extract was compared against a series of aliphatic and phenylsubstituted aliphatic acids by paper chromatography. The developing solvent used was propanol, 60 parts; ammonia, 30 parts and water, 10 parts (Buffs, Peters and Wakelin, 1951). Whatman No. 3 paper was used unbuffered and found to give more discrete spots than the thinner papers. The acids used for comparison were phenylpyruvic acid (freshly prepared), phenylacetic acid, $\beta$-hydroxy-butyric acid and $\alpha$-hydroxy-butyric acid. These derivatives of butyric acid were used because their smell in dilute aqueous solution was very similar to that of the urine. The chromatogram was run overnight 
(about 12 hours) dried in air and the spots developed by spraying the chromatogram with 'universal indicator' (B.D.H. Ltd.) adjusted to a purple colour with sodium hydroxide (Long, Quayle and Stedman, 1951). A more even spray was obtained when alcoholic potassium hydroxide was used to adjust the colour. The ammonium salts of the acids showed up as red spots on an originally purple background which quickly faded. The urine extract was found to give three acid spots of $\mathbf{R}_{\mathbf{F}}$ values $0.56,0.62$ and 0.76 . The slowest running spot was equivalent to that of phenylpyruvic acid and the others were equivalent to $\alpha$-hydroxy-butyric acid which itself gave rise to two spots. The fastest moving spots of both the urine and the pure $\alpha$-hydroxy-butyric acid $\left(R_{F} 0 \cdot 76\right)$ possessed the characteristic smell originally noticed in the urine. Pure phenylacetic acid had an $R_{F}$ of 0.75 and hence was not separable from the $\alpha$-hydroxy-butyric acid.

As a confirmation of the identity of the smell with $x$-hydroxy-butyric acid, a sample of the urine extract was allowed to stand at room temperature for a few days during which time the phenylpyruvic acid decomposed. This could be shown by a negative ferric chloride test and chromatographically, but the smell remained just as persistent. This old extract was also run in a different solvent system of butanol, 95 parts; formic acid, 5 parts; saturated with water (Lugg and Overell, 1948). The completed chromatogram was sprayed with 'universal indicator' but dried in air for a longer period than previously. Both the urine and the $\alpha$-hydroxy-butyric acid gave two spots each of $R_{F} 0.77$ and 0.85 but now in each case the smell was associated with the slower moving component.

The method of formation of the smell was investigated by producing further chromatograms of $\alpha$-hydroxybutyric acid in propanol ammonia in an atmosphere of cyanide (by placing in aqueous solution of potassium cyanide in a tank) to inhibit oxidation. The area of the fastest moving spot was relatively much smaller than previously. This suggested that the smell was due to an oxidation product of $\alpha$-hydroxy-butyric acid which had previously been increased in amount during chromatography.

Phenylacetic Acid. In the previous chromatograms one of the spots of $\alpha$-hydroxy-butyric acid had a very similar $R_{F}$ value to phenylacetic acid. Although we suspected the presence of the latter substance, proof had not been obtained. This was done by using a different solvent. This solvent was benzene, 40 parts; formic acid, 40 parts; and water, 20 parts (Bray, Thorpe and White, 1950). With it the old urine extract gave spots of $R_{F} 0 \cdot 23,0 \cdot 55,0 \cdot 77$ and $0 \cdot 88$. The three slower moving spots were the same as those given by $\alpha$-hydroxy-butyric acid and the fastest moving one was the same as that given by phenylacetic acid. The characteristic smell of the urine was associated with the spots with $R_{F}$ values of 0.55 and 0.77 and the different smell of phenylacetic acid was associated with the spot of $R_{F} 0 \cdot 88$.

Amino-acids. Routine two-dimensional ascending paper chromatography in phenol-water-ammonia and collidine-lutidine-water (Dent, 1948) was performed on the urine. This showed an excess of phenylalanine, methionine and tyrosine. A further modification consisted of evaporating the urine to dryness under reduced pressure and extracting the amino-acids with acetone. The acetone extract was compared with the other aminoacids by one-dimensional descending paper chromatography with the solvent propanol, 60 parts; ammonia, 30 parts; water, 10 parts. On dipping the dried chromatogram in $0.1 \%$ ninhydrin in acetone and drying for five minutes at $100^{\circ} \mathrm{C}$., large amounts of phenylalanine, methionine and tyrosine were demonstrated. There was, however, no evidence of $\alpha$-amino-butyric acid which had been suspected as the source of the $\alpha$-hydroxy-butyric acid.

All these results were confirmed in post-mortem urine.

\section{Discussion}

The child presented a clinical picture similar in some respects to that of phenylpyruvic oligophrenia. Unusual features were marked unresponsiveness to stimuli, muscular flaccidity, recurrent episodes of pyrexia with generalized oedema and a penetrating smell in freshly passed urine. This smell bore no resemblance to that of phenylacetic acid which is commonly associated with phenylketonuria. It effectively masked the smell of that substance which was also in the urine.

The urinary findings established that the baby had a metabolic defect producing phenylketonuria together with another abnormality leading to the excretion of $a$-hydroxy-butyric acid in the urine. The odour was so characteristic that it should be easy to recognize any further examples of this condition. The smell was probably due to an oxidation or polymerization product of $\alpha$-hydroxybutyric acid, since it was reduced in amount on paper chromatography in an atmosphere of cyanide. It was associated with a single spot except in chromatography performed in benzene, 40 parts; formic acid, 40 parts; water, 20 parts, in which two spots with the characteristic smell were found. The $\alpha$-hydroxy acids tend to polymerize together and to form lactones as shown in Fig. 1 for $\alpha$-hydroxy-
$2 \mathrm{CH}_{3} \mathrm{CH}_{2} \mathrm{CHOH} \mathrm{COOH} \longrightarrow$
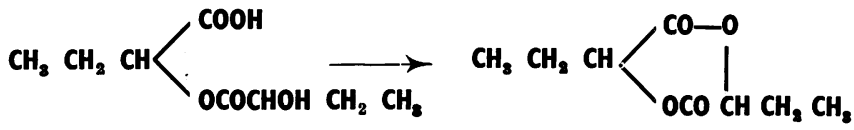

FIG. 1 . 
butyric acid. This should account for the multiple spots in chromatograms of this substance.

Abnormal excretion products other than phenylpyruvic acid have been detected in the urine of patients with phenylketonuria and are listed by mediary metabolism must at present remain uncertain. It is unlikely to be formed in the oxidation of fat since this leads to the formation of oxo- and hydroxy derivatives in the $\beta$ position. A possible source is from $\alpha$-amino-butyric acid and thence by

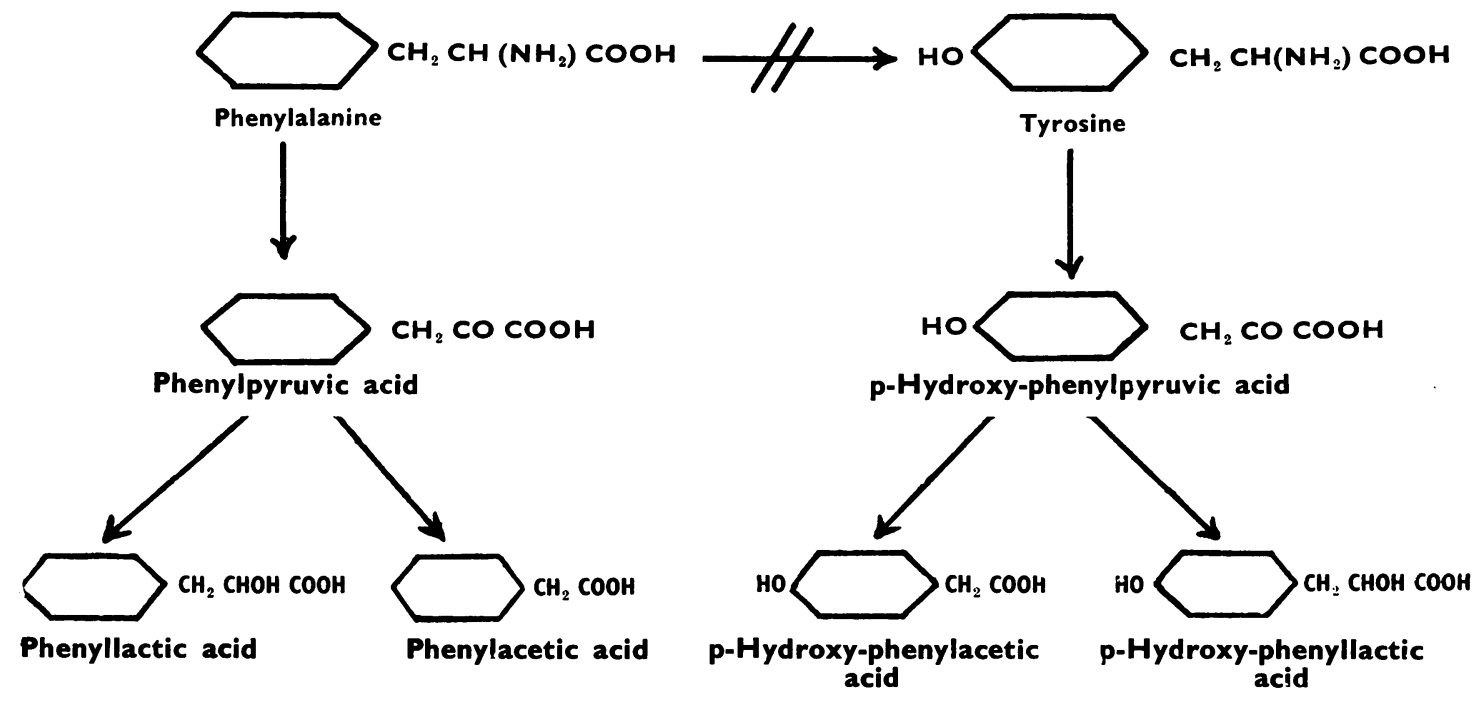

FrG. 2.

Jervis (1954). These are phenyllactic, p-hydroxyphenyllactic, phenylacetic, p-hydroxy-phenylacetic and o-hydroxy-phenylacetic acids. The chemical relationships between those substances are shown in Fig. 2 and it is probable that all can be derived from phenylalanine. Of these only phenylacetic acid was detected in the urine of the patient we are discussing. Normally the acids with a hydroxylated benzene reduction perhaps by bacteria to the $\alpha$-hydroxy compound as shown in Fig. 3. This type of hydrolytic deamination is known to take place in bacteria (Baldwin, 1947) and it is possible that bacteria in the renal tract were responsible for it in our patient. No urinary infection, however, was detected and the smell was present in freshly passed specimens, and within a few hours of birth. The

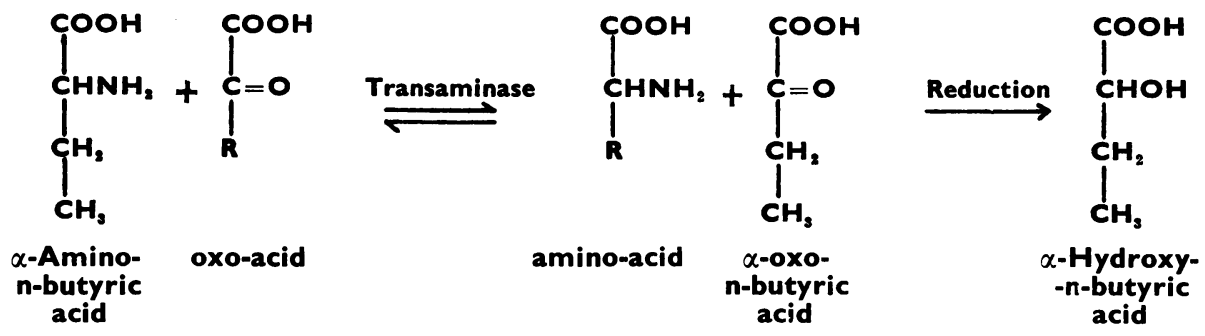

ring are derived from tyrosine, but in phenylketonuria it is possible they are derived from hydroxylation of the derivatives of phenylalanine.

The presence of $\alpha$-hydroxy-butyric acid cannot be explained from this system and its origin in inter- amino-acid analogue of $\alpha$-hydroxy-butyric acid, $\alpha$-amino-butyric acid, has been shown in human urine (Dent, 1947) but it was not detectable in our patient.

$\alpha$-Oxo-butyric acid may be linked to the meta- 
bolism of many other amino-acids as shown by experimentation in mutated bacteria. Carroll, Stacey and du Vigneaud (1949) have shown that $\alpha$-oxo-butyric acid occurs in the catabolism of homoserine and Lien and Greenberg (1953) have shown that the same compound occurs in the metabolism of threonine. It has also been shown by Umbarger and Adelberg (1951) that $\alpha$-oxobutyric acid can be used in the synthesis of isoleucine and valine from simpler substances. So far there has been no evidence of similar mechanisms in humans.

The absence of any signs during life or at necropsy of renal infection and the fact that the distinctive smell was present in fresh specimens of urine incline us against the view that the $\alpha$-hydroxy-butyric acid was produced wholly or in part by bacterial action. We regard it as more probable that its presence was due to a defect in intermediary metabolism and that this was a major factor in causing the child's illness.

\section{Summary}

A child is described in whom a syndrome of mental deficiency and recurrent episodes of oedema were associated with the urinary excretion of $\alpha$-hydroxy-butyric acid and phenylpyruvic acid.

The presence of $\alpha$-hydroxy-butyric acid gave rise to an unusual smell.
Phenylacetic acid, phenylalanine, tyrosine and methionine were also present in excess in the urine.

Some possible modes of formation of the $\alpha$-hydroxy-butyric acid are discussed.

We wish to thank Dr. A. L. Latner for his advice and criticism throughout the course of the investigation, and also Prof. S. D. M. Court and Dr. F. J. W. Miller for help in the preparation of this paper. We are grateful to Dr. J. Hart-Mercer for the necropsy report.

\section{REFERENCES}

Altmann, S. M., Crook, E. M. and Datta, S. P. (1951). Biochem. J, 49, Ixiii.

Baldwin, E. (1947). Dynamic Aspects of Biochemistrv, p. 213. Cambridge.

Berry, J. P. and Woolf, L. I. (1952). Nature (Lond.), 169, 202.

Bray, H. G., Thorpe, W. V. and White, K. (1950). Biochem. J., 46,

Buffa, P.. Peters, R. A. and Wakelin, R. W. (1951). Ibid., 48, 467.

Carroll, W. R., Stacy, G. W. and Vigneaud V. du (1949). J. biol. Chem., 180, 375 .

Cavallini, D., Frontali, N. and Toschi, G. (1949). Nature (Lond.), 164,792 .

Dent, C. E. (1947). Biochem. J., 41, 240.

(1948). Ibid., 43, 169.

Herbst, R. M and Shemin, D. (1939). Organic Syntheses, 19, 1 and 77. New York and London.

Jervis, G. A. (1954). In Genetics and the Inheritance of Integrated Neurological and Psychiatric Patterns, Res. Publ. Ass. nerv. ment. Dis., 33, 259.

Lien, O. G. and Greenberg, D. M. (1953). J. biol. Chem., 200, 367. Long, A. G. Quayle, J. R. and Stedman, R. J. (1951). J. chem. Soc., p. 2197.

Lugg, J. W. H. and Overell, B. T. (1948). Aust. J. sci. Res., Ser. A, $1,98$.

Smith, F. J. and Jones, E. (1948). A Scheme of Qualitative Organic Analysis, p. 37. London.

Umbarger, H. E. and Adelberg, E. A. (1951). J. biol. Chem., 192 883. 